\title{
The Nonlinear Dynamics Simulation of Drill String-drill Bit-rock Based on ABAQUS
}

\author{
Jin Shi, Jianwei Wang*a ${ }^{\mathrm{a}}$ Xianglei Liu \\ College of Mechanical Engineering, \\ Dalian University, \\ Dalian, 116622, China \\ a858981646@qq.com
}

\begin{abstract}
This paper tries to use the finite element analysis software ABAQUS to build the model and get images of rock stiffness degeneration, then get the displacement velocity and acceleration curves of drill and drill bit to express the longitudinal, transverse and torsional vibrations, as well as random access collision with hole wall . It aims at analyzing the incremental changes in these structure of rocks when destruction and disturbance happens in order to avoid the drilling accident which caused by the changes which are difficult to observe in the general physics experiment.
\end{abstract}

Keyword-Simulation; Drill String; Drill Bit; Rock; ABAQUS

\section{INTRODUCTION}

The key to drilling system is an effective forecasting and control on downhole drill bit and drill string dynamics and movement rules. therefore, one of its basic work is to set up a reasonable and reliable dynamic model to find the movement rules and mechanical properties of drill string and drill bits underground[1].Drilling system dynamics is a study of mechanical behaviors which studies drill string, drill bits, rock, and drilling fluid under various drilling conditions. In the process of drilling, drill and drill bits are working in the narrow hole, which are both full of drilling fluid inside and outside[2]. They are under tension, compression, bending and twisting and hydraulic loading.The vibration is the coupling of transverse direction, axial direction, and torsion, while the equation is nonlinear. Because the drilling system is huge and complicated, so it cannot be studied by physical experiments[3].

Based on reasonable assumptions of finite element model, this paper uses FEM software ABAQUS to model the drilling system.This paper aims at using the powerful nonlinear FEM software, ABAQUS, to make an emulation analysis of the drilling system, and then, to effectively predict and control the dynamics and motion of drill bit and underground drills. In addition, the control of borehole trajectory is realized which can be a guidance to actual drilling operations.

\section{NONLINEAR DYNAMIC MODEL OF DRILLING SYSTEM}

\section{A. The mechanical model of interaction between drill bits and rock}

In the process of drilling,a drill gets a longitudinal force which mainly come from WOB, the reaction of the rock and the dynamic load of the drill itself.in every moment the drill bits are under the reactions of all these forces and must maintain balance, thus, a longitudinal force equations of drill bits and rock can be set up as follows.

$$
\mathrm{P}(t)+M_{b} a(\mathrm{t})+F_{z}(t)=0
$$

In the formula, $\mathrm{P}(\mathrm{t})$ is the drill press acting on the drill bit at any moment.Drill quality is Mb;Acceleration of the drill is a ( $t$ ) at any moment; Vertical reaction force caused by rock is $\mathrm{Fz}(\mathrm{t})$ at any moment.

At any time,the transverse force is resultant of all transverse force on tooth surface contacting with rock at this moment.It can be decomposed in the $\mathrm{X}, \mathrm{Y}$ direction,the formula is as follows:

$$
\begin{aligned}
& \left\{\begin{array}{l}
\mathrm{F}_{l x}(t)=\sum_{i} F_{\mathrm{i}(t)}^{*} \cos \left(\pi+T_{i(t)}\right) \\
F_{l y}(t)=\sum_{i} F_{i(t)}^{*} \sin \left(\pi+T_{i(t)}\right)
\end{array}\right. \\
& i \in[1,6]
\end{aligned}
$$

In the formula, $\mathrm{Ti}(\mathrm{t})$ is the direction of the $\mathrm{i}$ blade scraping at $\mathrm{t}$ time. In addition to these forces, drill bits bearing moment of resistance effect, which caused by cutting resistance, the moment of resistance and torque, which acting on the drill bit, should be equal. Suppose at $t$ time, the coordinates of any point in i-scraper`s surface`s ,which contact with the rock ,is $x i(t), y i$

(t),zi(t),establish moment equilibrium equation for drill bits as follows:

$$
\mathrm{M}_{R}(\mathrm{t})=\sum_{i} l x \mathrm{i}(t) f_{l x i}(t)+\sum_{i} l y i(t) f_{l y i}(t)
$$

In the formula,lxi(t) and lyi(t) is the distance of the I blade surface between $\mathrm{x}$ axis and $\mathrm{y}$ axis in time $\mathrm{t}$ on drill bits coordinate system.flxi(t)、 flyi(t) is the component force of transverse force between the I blade surface and rock at $\mathrm{x}$ axis and $\mathrm{y}$ axis.

\section{$B$. The drill string dynamics model}

Equations of second order differential equations can describe the drill string system dynamics.

$$
[\mathrm{M}]\{\ddot{\mathrm{u}}\}+[C]\{\dot{u}\}+[K]\{u\}=\{F(t)\}
$$

In the formula, $[\mathrm{M}]$ is the mass matrix, [c] is the damping matrix, $[\mathrm{k}]$ is the stiffness matrix and $\mathrm{F}(\mathrm{t})$ is the 
load function change over time. $\{\ddot{u}\},\{\dot{u}\}$ and $\{u\}$ is nodal acceleration vector, velocity vectors and displacement vector.Use energy method and finite element method can deduce mass, damping, and stiffness matrices in local coordinates,then by coordinate transformation can get global coordinate system dynamics model of drill string[6] .

\section{BASIC ASSUMPTIONS}

As the actual situation is more complex, factors more difficult to direct simulation it is necessary to make certain assumptions on this model. Specific assumptions are as follows:

(1). In the vertical wells, before drilling, the drill axis coincides with the axis of the hole, and there is no initial deformation.

(2). In the process of drilling, drill stem and drill collar material is linear elastic.

(3). Drill string and borehole wall direct contact is random elastic collisions.

(4).Drill geometry, material properties are constant, regardless of connection drill collar and local stiffness of holes and grooves.

(5). The drill is rigid body structure, does not deform.

(6). Ignore the damping effect of the mud, only buoyancy.

\section{CREATING FINITE ELEMENT MODELS}

\section{A. Mechanical properties of drill string}

Drill is a section of the ring beam elements. Its length is $1000 \mathrm{~m}$ and diameter is $127 \mathrm{~mm}$ and thickness is $7.5 \mathrm{~mm}$. Modulus of elasticity (young's modulus) $\mathrm{E}=1.7 \times 10^{11} \mathrm{~Pa}$;Poisson's ratio $\mathrm{u}=0.3$; Density $\sigma=6800 \mathrm{~kg} / \mathrm{m}^{3}$ (Taking into account the buoyancy). Used for calculation process will be defined as a linear elastic materials.

\section{B. Bit model}

Bits is scraper bit which often used for coal drilling. Quality $35 \mathrm{Kg}$, owing to the neglect of drill wear in drilling process, sets the bit to rigid bodies and defines the reference point.

\section{The mechanical properties of rocks}

Parameters of rock model

Diameter of the rock model is $320 \mathrm{~mm}$,and the thickness is $80 \mathrm{~mm}$. Damage model

to Druker-Prager As the criteria. The main parameter settings of rock shown in table 1 and table 2
TABLE 1. DUCTILE DAMAGE

\begin{tabular}{|l|l|l|l|}
\hline & Fracture Strain & Stress Triaxiality & Strain Rate \\
\hline 1 & 0.025 & -0.33 & 0 \\
\hline 2 & 0.01 & 0 & 0 \\
\hline 3 & 0.005 & 0.33 & 0 \\
\hline
\end{tabular}

TABLE 2. DRUKER－PRAGER

\begin{tabular}{|l|l|l|l|l|l|}
\hline & $\begin{array}{l}\text { Young`s } \\
\text { Modulus }\end{array}$ & $\begin{array}{l}\text { Poisson`s } \\
\text { Ratio }\end{array}$ & $\begin{array}{l}\text { Angle } \\
\text { of } \\
\text { Friction }\end{array}$ & $\begin{array}{l}\text { Flow } \\
\text { Stress } \\
\text { Ratio }\end{array}$ & $\begin{array}{l}\text { Dilation } \\
\text { Angle }\end{array}$ \\
\hline 1 & $2 \mathrm{E}-10$ & 0.3 & 30 & 0 & 15 \\
\hline
\end{tabular}

D. Assemble and define the analysis step

Fit together the all components, to ensure that they are in the correct position. Under normal circumstances, a complex finite element analysis may contain a number of interrelated events, according to order of occurrence, define the corresponding analysis step in the step module. In this article, defines the analysis step is display dynamics and the algorithm is the central difference method.

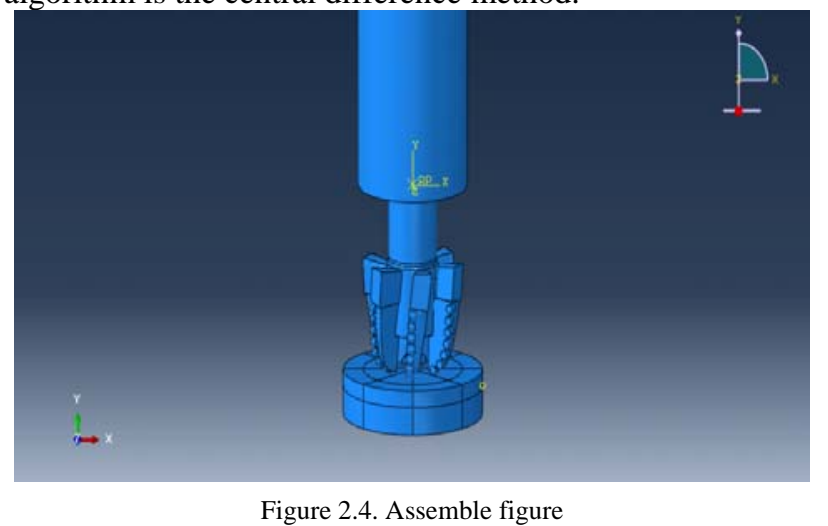

\section{E. Define the interactions}

The contact between the inner surface of the wall and the outer surface of drill string is surface contact. Set the coefficient of friction is 0.2. Mechanical constraint formulas for penalty function method. The contact between bit and rock is general contact. Interface is the tooth surface of bit and the inner surface of the rock. In order to ensure drill string and drill bit can interact, set the reference point of the bit and drill the bottom ends are connected.

\section{F. Define the boundary conditions and loads}

In order to more closely simulate the drilling process, defined the underside of rocks and the top of the wall to be fixed. The degrees of freedom of the side surface of the rock, in addition to the displacement of U2 direction, are completely restricted. The U2 direction speed is set to $60 \mathrm{R} / \mathrm{min}$, Drilling pressure is set to $120 \mathrm{KN}$.

\section{G. Meshing}

In the simulation experiment needs to mesh parts, To enable the grid to describe the force on the target. Contact 
area for grid refinement, non-contact areas use a coarse mesh to save resources. Bit cell type to R3D4,drilling string cell type to B31,Rock cell type to C3D8R.

\section{RESULTS AND ANALYSIS}

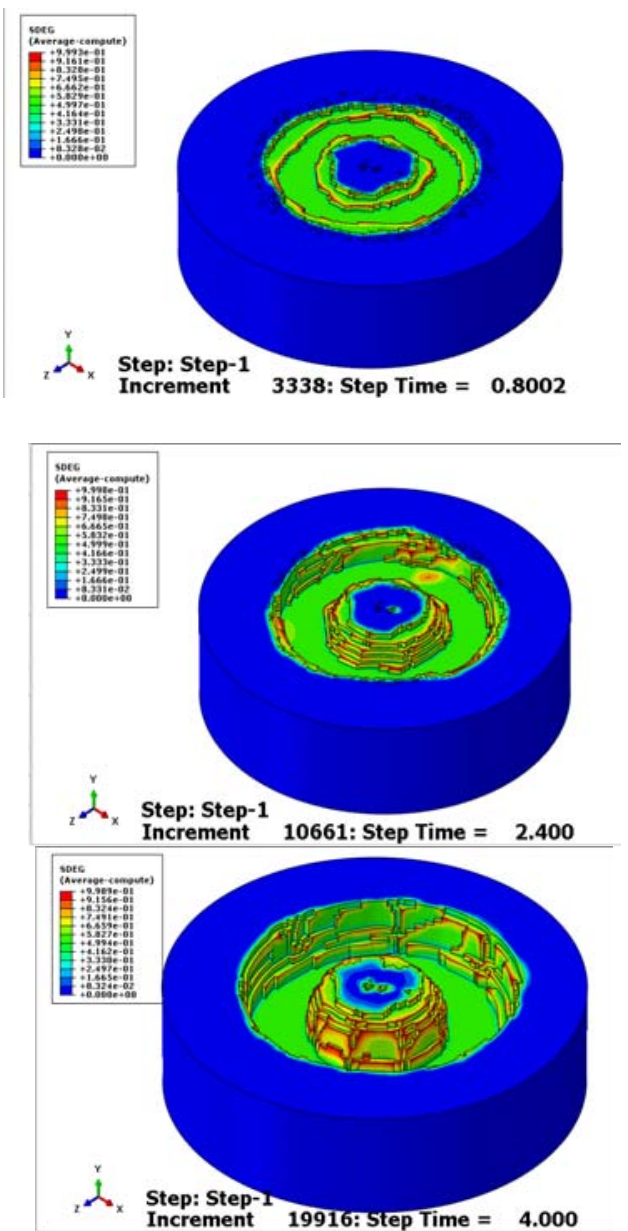

Figure 3.1. The image of stiffness degradation degree of rock in different times

Figure 3.1 is at different times the image of stiffness degradation degree of rock. Because the rock has a certain degree of elasticity and plasticity, throughout the cutting process can be thought of as a metal cutting process. Under the action of axial load and horizontal load, drag bit cutting edge continued to eat into the formation, The rocks in front of the cutting edge under the effect of tangential force constantly produced plastic flow to cutting and breaking. As can be seen from the figure3.1, bits constantly down cutting, range of stiffness degradation model of rock to expand. In the process of cutting,

When equivalent plastic deformation of rock more than the material itself set failure criteria values, element will to be deleted.
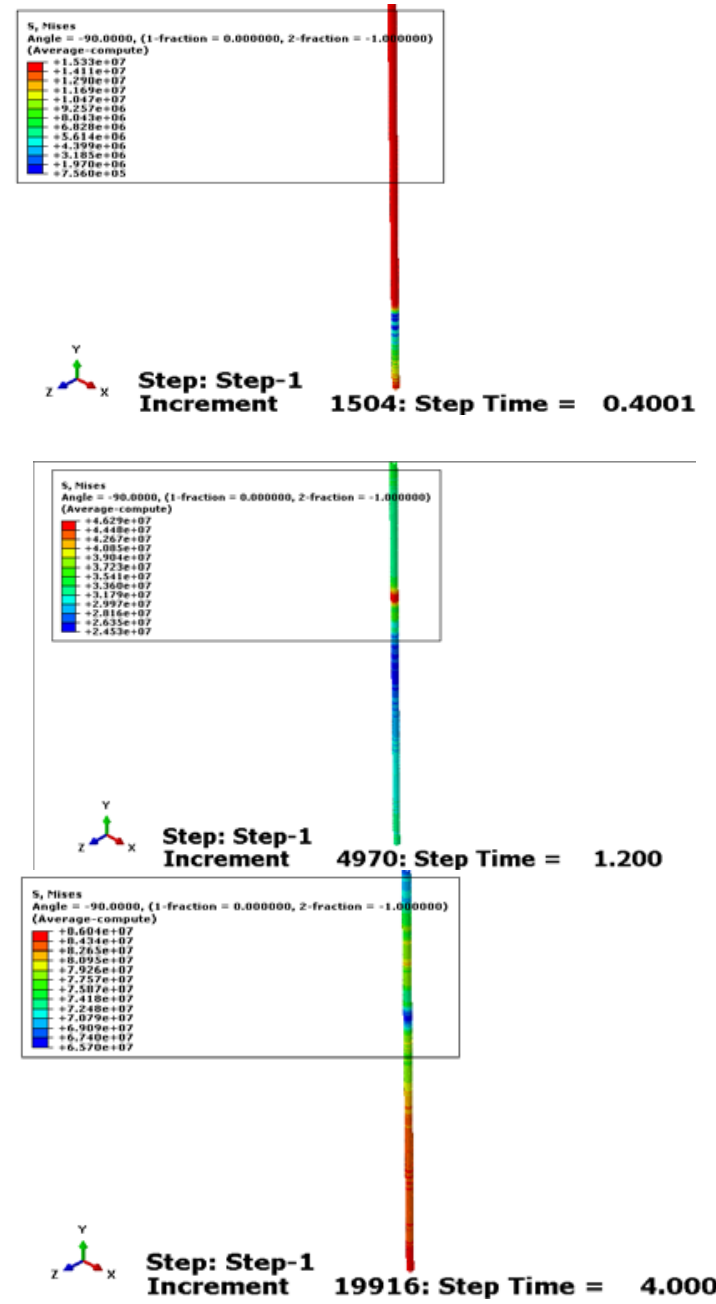

Figure 3.2. Mieses images of drill string in different time

Figure 3.2 is at different time mieses images of drill string. As can be seen from the figure3.2, at the time of beginning of drilling, stress concentration likely to occur at the top of the drill string, when the drill string continued down the feed, Stress concentration easily at the bottom of the drill string. In order to ensure the safety, use the high strength of drill string at bottom. 


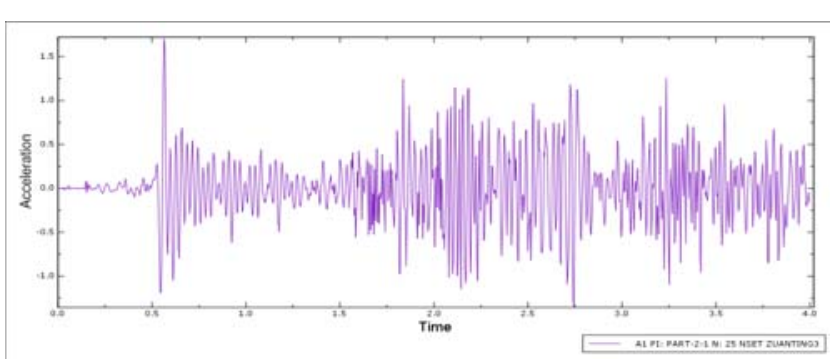

Fig.3.3(a)

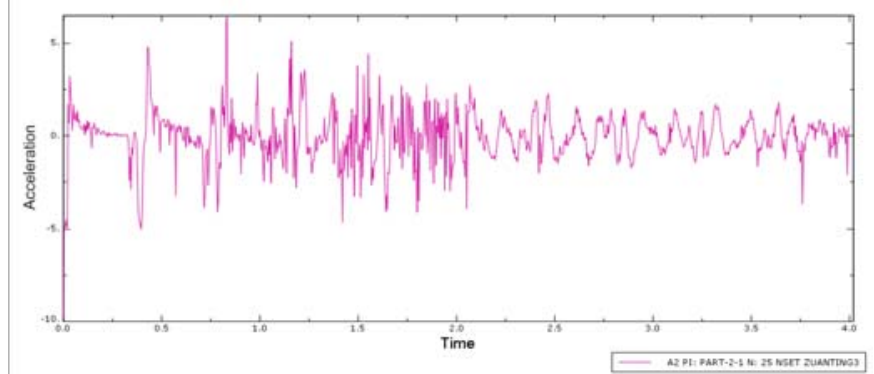

Fig.3.3(b)

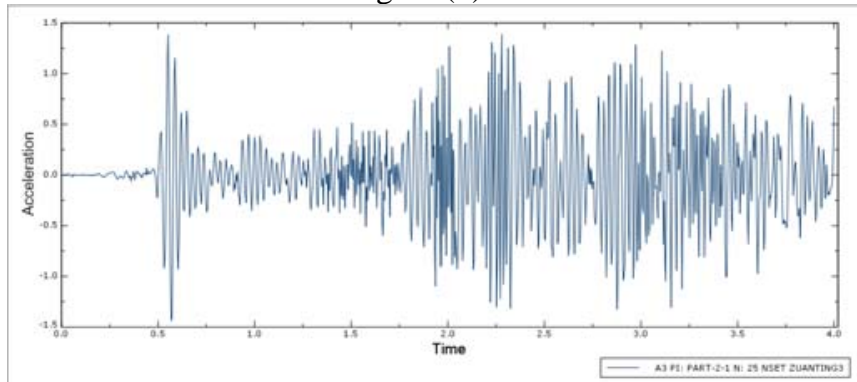

Fig 3.3(c)

Figure 3.3. Acceleration time history curve of 3rd node in all directions of drill string

Figure 3.3(a)and (c) is the acceleration time history curve of 3rd node in the horizontal direction of drill string. It can be seen from the figure, at the beginning of drilling, maximum vibration occur in about 0.5 seconds, after about 0.5 seconds vibration amplitude began to decrease and stabilize. And in about 2 seconds, vibrating amplitude once again reached the maximum and presented certain regularity.

Figure 3.3 (b) is the longitudinal acceleration time history curve of drill string. It can be seen from the figure, Change of vertical vibration acceleration is more complex and with a distinctly nonlinear nature, and change of waveform without rules. Maximum vibration amplitude occur in about 0.5 seconds, after 2 seconds vibration decreased significantly. It could be concluded that collapse of the drill bit and breakage of drill string often occurs in the drill bit comes into contact with hard rock.

\section{CONCLUSIONS}

(1).After drilling started, violent cutting actions happened between drill bit and rocks which can be seen from the image. In the process of cutting, when the equivalent plastic deformation of a rock exceeds the value that set by the failure criteria in the material itself, the rock element loses its efficacy.

(2).After drilling started, the range of stress concentration on the drill string will move to the downward drill string. Wider vibration easily happened when the drill bit contacts the rock. Afterwards, the vibration will change regularly at horizontal direction and obvious non-linear vibrations which are in disorder take place at longitudinal direction.

(3).The collapse of the drill bit and breakage of drill string often occur when the drill bit just contacts the rock and stress concentration is likely to happen in the bottom of the drill string, Therefore, in order to keep the safety of borehole, a bigger sized drill string should be chosen at the bottom.

\section{ACKNOWLEDGEMENTS}

The project is partly supported by National Nature and Science Foundation (No.51275061, 50975033), Doctoral Starting Foundation of Dalian University and University Students' innovative project (No.2013028, 201411258031).

\section{REFERENCES}

[1] Zhu C Z,Xie Y C,Liu Q Y,2003. Nonlinear coupling dynamic simulation of drill-string system. Journal of ordnance, 24(1):85-88.

[2] Liu Q Y,Meng Q H,Pang X D, 2009.Study and application of dynamics of drilling system. Beijing: Science press.

[3] Xiao W S,Zhong Y F,2008. Top drive drilling dynamics and its virtual prototype design system. Beijing: petroleum industry press.

[4] Wang M,Li G Y,2014. Numerical simulation analysis on rock cutting. Study and application of mechanical,27(2): 115-123.

[5] Si H B,Cai Z Y,2011. Research on building soil constitutive model based on ABAQUS. Rock and soil mechanics, 32(2): 599-603.

[6] Zhu C Z,Feng D H,Lu B,Yang Y X,2011.Study on Nonlinear coupling dynamic of drill structure -shaft wall- rock. Chinese Journal of mechanical engineering, 43(5): 145-149.

[7] Wang J F,Zhang J,Zhang T T,Han T,2012, Deformation analysis of deepwater drill based on Abaqus.Liao Ning chemical industry, 41(10): 1071-107.

[8] Wu K S,Liao F L,2014. Study on after rock cutting injury breaking law of PDC tooth . Petroleum machinery, 42(5): 29-33

[9] Kuang C Y,Ma D K,Liu Q Y,Wu Z B,2001. Dynamic behavior simulation of Drill string-bit-rock system.22(3): 81-85. 